BMJ Open

Diabetes

Research

\& Care

\title{
Blood glucose self-monitoring and internet diabetes management on A1C outcomes in patients with type 2 diabetes
}

\author{
Nelson Chow, ${ }^{1}$ Daniel Shearer, ${ }^{2}$ Jessica Aydin Plaa, ${ }^{3}$ Betty Pottinger, ${ }^{3}$ \\ Monika Pawlowska, ${ }^{4,5}$ Adam White, ${ }^{4,5}$ Hugh D Tildesley ${ }^{4,5}$
}

To cite: Chow N, Shearer D, Aydin Plaa J, et al. Blood glucose self-monitoring and internet diabetes management on $\mathrm{A} 1 \mathrm{C}$ outcomes in patients with type 2 diabetes. BMJ Open Diabetes Research and Care 2016;4:e000134. doi:10.1136/bmjdrc-2015000134

Received 13 July 2015 Revised 9 March 2016 Accepted 15 March 2016
CrossMark

For numbered affiliations see end of article.

Correspondence to Dr Monika Pawlowska; EndoDocMP@gmail.com

\section{ABSTRACT}

Objectives: The purpose of this study was to determine any correlation between frequency of selfmonitoring of blood glucose (SMBG), frequency of patient-provider communication of SMBG (reporting), and hemoglobin $\mathrm{A} 1 \mathrm{C}$ for patients with non-insulindependent diabetes solely on oral medications.

Research design and methods: 191 charts of patients with type 2 diabetes treated solely with oral hypoglycemic agents were reviewed retrospectively. $\mathrm{A} 1 \mathrm{C}, \mathrm{SMBG}$ frequency, and frequency of online communication with an endocrinologist within the most recent 6-month period were used in the analyses. Regression analysis was used to determine correlations to $\mathrm{A} 1 \mathrm{C}$. For subsequent subgroup analysis, patients were separated into infrequent and frequent SMBG groups, defined as those who test on average once or less per day or twice or more per day.

Results: Although testing frequency did not correlate with $\mathrm{A} 1 \mathrm{C}$, higher reporting frequency correlated with lower A1C. Subgroup analysis of the frequent SMBG group showed a significantly lower $\mathrm{A} 1 \mathrm{C}$ in frequent reporters when compared to infrequent reporters $(\mathrm{N}=118, \mathrm{p}<0.05)$. This trend was not observed in the infrequent SMBG group ( $\mathrm{N}=73, \mathrm{p}=0.161)$.

Conclusions: The inverse correlation between reporting frequency and $\mathrm{A} 1 \mathrm{C}$, as well as the significant difference in $\mathrm{A} 1 \mathrm{C}$ only for the frequent testers, suggests that frequent SMBG has an effect on reducing $A 1 C$ only when combined with regular, frequent communication of SMBG with a healthcare provider.

The day-to-day management of diabetes mellitus is a complex and consistent challenge for patients and healthcare providers alike. Established patient self-management tools, such as self-monitoring of blood glucose (SMBG), are now being used in tandem with information technology and telecommunications to provide a more integrated management of the disease.

The benefits of intensive glycemic control have long been established both in type 1 and type 2 diabetes, and include reduced

\section{Key messages}

- Frequency of self-monitoring of blood glucose not found to affect $\mathrm{A} 1 \mathrm{C}$ in non-insulin-dependent diabetes.

- Frequency of submission of online reports of blood glucose found to be correlated with A1C and frequency of self-monitoring of blood glucose.

- For patients who tested frequently, a difference in $\mathrm{A} 1 \mathrm{C}$ was found between reporting frequently and infrequently, where no difference was found in those who tested infrequently.

rates of microvascular complications, ${ }^{1}{ }^{2}$ with SMBG providing the means to monitor progress and avoid hypoglycemia. ${ }^{3}$ Although SMBG is well supported for frequent use in insulin-dependent diabetes, ${ }^{4-8}$ there is controversy over self-testing in non-insulindependent type 2 diabetes and a lack of research on the importance of testing frequency on clinical outcomes. ${ }^{9}$

One line of reasoning as to why SMBG cannot consistently be shown to demonstrate an effect in non-insulin-dependent diabetes lies in the variability of decision-making as a result of SMBG. ${ }^{10}$ With the advent of online communications, the Internet-based Blood Glucose Monitoring System (IBGMS) is a technology that is used to augment SMBG by giving patients the means to communicate their blood glucose levels to their healthcare provider for actionable feedback. This technology has been shown to reduce A1C in several randomized controlled trials for type 1 and type 2 diabetes. ${ }^{11-13}$

The purpose of this study was to evaluate the relationship between $\mathrm{A} 1 \mathrm{C}$, frequency of SMBG, and frequency of IBGMS reporting for patients with type 2 diabetes solely on oral medications. 


\section{RESEARCH DESIGN AND METHODS}

IBGIMS procedure

Patients recommended for IBGMS by their healthcare provider met with a research coordinator immediately following their clinical appointment for training on submitting reports. Patients were instructed to test their blood glucose before each meal and to report back every 2 weeks. Standardized reports providing the mean, $\mathrm{SD}$, and range of daily glucose values were sent to a healthcare provider through a variety of methods, reflecting the individual patient's own comfort with technology. Patients reported online through meter software, a spreadsheet, or a simple online platform that allowed a healthcare provider to review each report and provide brief (typically 2-4 sentences) feedback to the patient. Necessary adjustments to each patient's oral medications were communicated, and positive reinforcement was provided if no changes were needed. It is important to note that IBGMS reporting operated in parallel with the conventional standard of diabetes care; although IBGMS patients have been shown to visit their endocrinologists less frequently, ${ }^{14}$ they were offered the same short-term and yearly follow-up appointments as non-IBGMS patients.

\section{Data collection}

Chart data from 229 patients with type 2 diabetes registered for IBGMS within the past 3 years were evaluated. To be considered for the study, patients must have been taking oral agents alone for their type 2 diabetes, with a minimum of one IBGMS report submitted. A total of 191 patients fit the criteria and were used in the final analyses, while the remaining 38 had not submitted a report or were not treated solely on oral agents. Age and weight were collected as confounding variables to be controlled for, while frequency of SMBG and frequency of IBGMS reporting were used as the explanatory variables. SMBG frequency was defined as the average number of tests taken per day, calculated for each patient on the basis of their most recent report sent in to the healthcare provider. The reporting frequency was defined as the average number of reports per 3 months over the most recent 6 -month period. A1C was collected and averaged over the same 6-month period for each patient and used as the response variable. Duration of diabetes, presence of diabetes complications (cataracts, retinopathy, nephropathy, neuropathy, arteriosclerotic heart disease, peripheral vascular disease or stroke), and the oral medication regimen of each patient during the study period were recorded for further insight into the patient subgroups.

\section{Statistical methods}

Simple and multiple regression analyses were performed using the statistical software $\mathrm{R}$ to determine correlation coefficients and significance values. One-way analysis of variance tests were used to assess a relationship between diabetes complications and testing and reporting frequency. Welch's two sample t test was used for analyzing the baseline characteristics due to the higher total sample number. Wilcoxon rank-sum tests were used to determine statistically significant differences in the subgroup analysis; Pearson's $\chi^{2}$ test was used to test for significant differences in diabetes complications and medication regimes.

\section{RESULTS}

A multiple regression analysis using age, weight, frequency of testing, and frequency of reporting as parameters showed that frequency of reporting had an inverse correlation to A1C $(\mathrm{p}<0.05)$, whereas frequency of SMBG, age, and weight did not show statistical significance $(p=0.158, p=0.068, p=0.195)$. A simple regression using only frequency of reporting similarly shows an inverse correlation with A1C $(\mathrm{p}<0.05)$, as shown in figure 1A. No relationship was observed between the number of diabetes complications present for each patient and their testing or reporting frequency $(\mathrm{p}=0.526$ and $\mathrm{p}=0.642)$.

To examine the effect that frequency of reporting had on frequency of SMBG, a simple regression analysis was performed using frequency of reporting as the dependent variable against frequency of testing. As seen in
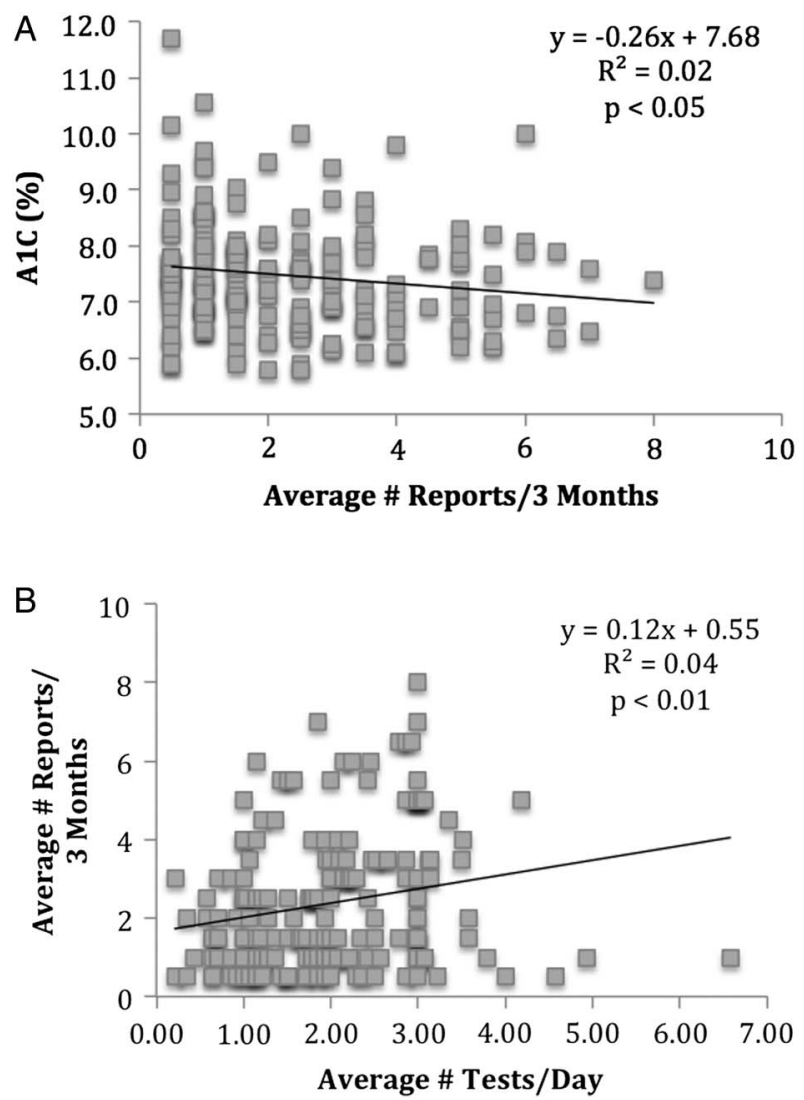

Figure 1 Linear regression demonstrating $(A)$ a trend of reduced $A 1 C$ with higher reporting frequency and $(B)$ a trend of increased reporting frequency with testing frequency. 
figure $1 \mathrm{~B}$, it was found that there was a positive correlation between the two $(\mathrm{p}<0.01)$.

Since frequency of reporting and SMBG were shown to be correlated, we examined further as to whether frequency of reporting and SMBG together produced an interactive effect on $\mathrm{A} 1 \mathrm{C}$, treating the two predictors as continuous variables. No statistically significant interaction was observed (data not shown). Subsequently, the data set was divided into infrequent and frequent testers as defined by those who tested their blood sugars on average once or less per day or twice or more per day. The sub-categorization of infrequent and frequent testers was empirically determined from clinical observations of the most common patient preferences toward daily testing. Patients testing an intermediate number of times between the two groups were rounded up or down accordingly.

Within those two groups, the data were further divided into infrequent and frequent reporters, as defined by those who report once or fewer times every 3 months, or more than once every 3 months. The interval of one report per 3 months was selected to simulate the frequency of follow-ups an endocrinologist might have with a patient, but all reporters in both groups were virtually receiving more contact with their endocrinologist than typically provided. To best manage both the unequal distributions and large difference in sample size ultimately present between the two subgroups, the Wilcoxon rank-sum test was used to test for significant differences in A1C.

Table 1 summarizes the baseline characteristics of the infrequent and frequent testing groups, with no

Table 1 Baseline characteristics and oral medication regimens among the infrequent and frequent testing groups

\begin{tabular}{llll}
\hline & $\begin{array}{l}\text { Infrequent } \\
\text { testers }\end{array}$ & $\begin{array}{l}\text { Frequent } \\
\text { testers }\end{array}$ & p Value \\
\hline $\mathrm{N}$ & 73 & 118 & \\
Age & $63 \pm 12$ & $65 \pm 11$ & 0.062 \\
Gender (male) & $40(54.7 \%)$ & $57(48.3 \%)$ & 0.383 \\
Weight (kg) & $89.5 \pm 24.3$ & $82.7 \pm 23.6$ & 0.347 \\
$\begin{array}{l}\text { Duration of } \\
\text { diabetes }\end{array}$ & $15 \pm 7$ & $16 \pm 9$ & 0.325 \\
$\begin{array}{l}\text { A1C } \\
\text { (\%, mmol/mol) }\end{array}$ & $\begin{array}{l}7.3 \pm 0.9 \\
(56 \pm 10)\end{array}$ & $\begin{array}{l}7.5 \pm 1.0 \\
(58 \pm 69)\end{array}$ & 0.123 \\
$\begin{array}{l}\text { Diabetes } \\
\text { complications }\end{array}$ & $45(61.6 \%)$ & $87(73.7 \%)$ & 0.081 \\
Metformin only & $19(26.0 \%)$ & $16(13.6 \%)$ & $0.033^{*}$ \\
$\begin{array}{l}\text { Metformin } \\
\text { +Sulfonylurea }\end{array}$ & $18(24.7 \%)$ & $24(20.3 \%)$ & 0.486 \\
Metformin & $16(21.9 \%)$ & $33(28.0 \%)$ & 0.349 \\
+Sulfonylurea & & & \\
+DPP-4/GLP-1 & & & \\
$\begin{array}{l}\text { Other } \\
\text { No data }\end{array}$ & $19(26.0 \%)$ & $36(30.5 \%)$ & 0.445 \\
\hline
\end{tabular}

Error is expressed in $95 \%$ Cls. A **' label denotes a significant difference between groups. significant differences in age, weight, duration of diabetes or A1C. An overview of the oral medications taken by both groups during the study period is also provided; there was only a significant difference observed between groups in the proportion of patients taking Metformin solely for their diabetes management $(p=0.033)$. There was no significant difference in the presence of diabetes complications between the two groups $(p=0.081)$, with 132 of 191 patients experiencing at least one complication overall.

As seen in figure 2, the frequent tester group showed a statistically significant decrease in A1C from $7.9 \pm 0.4 \%$ $(63 \pm 5 \mathrm{mmol} / \mathrm{mol}) \quad$ to $7.4 \pm 0.2 \% \quad(57 \pm 2 \mathrm{mmol} / \mathrm{mol}$, $\mathrm{p}<0.05)$ when comparing infrequent and frequent reporters. The infrequent testing group did not show a similar statistically significant decrease.

\section{DISCUSSION}

Testing two or more times a day, when combined with frequent reporting to a healthcare provider, was shown to be associated with a lower A1C in type 2 patients solely on oral medications. This finding supports the conclusion that a high degree of both patient and provider involvement in SMBG increases therapeutic effectiveness in this demographic.

The frequency of SMBG alone was not correlated to A1C, a finding consistent with previous investigations. ${ }^{9}$ While frequent SMBG has been shown previously to correlate with a lower $\mathrm{A} 1 \mathrm{C}$ in patients with type 1 diabetes, $(15,16)$ this relationship was not observed in the noninsulin-dependent type 2 patients in this study. This difference may be reasonably explained by the fact that there is no ubiquitous response to blood sugar readings for patients that do not take insulin. Type 1 patients can be provided with very clear guidelines on adjusting their day-to-day insulin doses in response to their blood sugar readings, while type 2 patients often must juggle multiple oral medications along with diet and exercise. Without timely feedback from their healthcare provider, type 2 patients may not be equipped to make meaningful use of the information gained by testing their blood sugars at a high frequency.

As an established method for bridging the gap between clinic visits and ultimately reducing patient A1C, ${ }^{17}$ a higher frequency of reporting using the Internet Blood Glucose Monitoring System (IBGMS) was shown to correlate with a lower A1C in non-insulin-dependent patients with type 2 diabetes. Interestingly, a positive correlation was found between SMBG frequency and reporting frequency, suggesting that highly compliant patients undergoing SMBG therapy may be strong candidates for the successful addition of IBGMS reporting. Further investigation into an interactive effect between SMBG and reporting suggests that only frequent testers may see the benefit of reporting their sugars. Only the subgroup of patients testing their blood sugars roughly two times a day or more showed a significant drop in A1C between infrequent 
Figure 2 Subgroup comparison

of differences in average $\mathrm{A} 1 \mathrm{C}$

when reporting more or less

frequently, as grouped into $(A)$

infrequent testers and $(B)$

frequent testers.
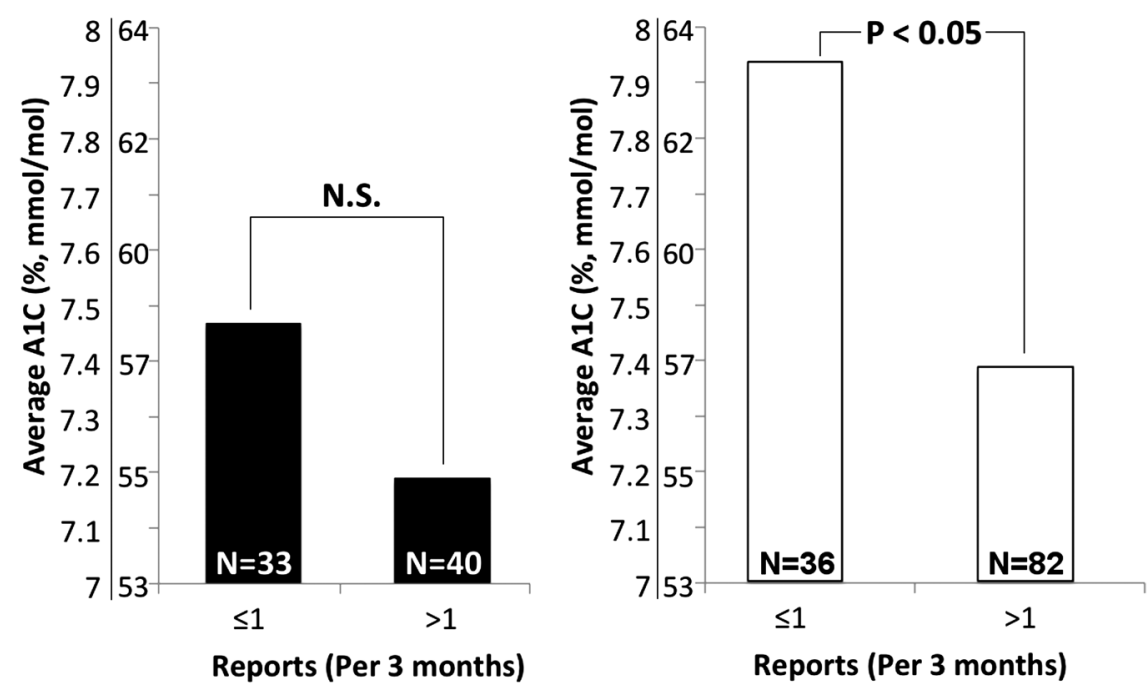

and frequent reporters. No apparent benefit in reporting was observed in the more infrequent testing subgroup.

As a retrospective chart review, the causative effect of testing and reporting on A1C must be interpreted with caution. Just as testing and reporting may influence A1C, consideration must be given to the possibility that A1C itself may influence patient behaviors through associated frequency of adverse events, acute symptoms, or other reasons. As suggested by the significantly higher proportion of infrequent reporters on Metformin therapy, other factors such as intensity of treatment may also affect patient behaviors. The correlations determined via regression analyses, while statistically significant, have low $\mathrm{R}^{2}$ values, indicating a significant level of unexplained variance in the model. This is to be expected to some degree due to the fact that the test parameters are affected by behavior, something inherently difficult to account for in our statistical model. Despite these shortcomings, the conclusions of this study are in accordance with similar findings in a type 2 randomized control trial for insulin-dependent patients. ${ }^{11} 12$

Owing to the limited scope of the study, certain features of the data set are important to note. The time frame for each individual's data was not controlled for, leading to differences in reporting consistency as well as potential differences between those recently enrolled in the program and those that have been reporting for a year or more. The therapeutic effect of IBGMS has been observed to dissipate after discontinuation on the program, however, ${ }^{11}$ suggesting that there may be minimal long-term effects on patient behaviors at play. It is worth noting that the patient subgroupings were unequally distributed, thereby affecting the statistical power in the frequent tester group and resulting in less power in the infrequent group to detect differences. A more robust study, able to maintain statistical power while subdividing patients by diabetes history and treatment in a more balanced manner, would help to mitigate these factors. Despite this, as IBGMS is offered as a treatment option to all patients at this clinic, the patients sampled would ideally represent a generalized type 2 population of clinical significance.

This study demonstrates that only a combination of both frequent blood glucose self-monitoring and frequent communication with a healthcare provider may have an effect in lowering $\mathrm{A} 1 \mathrm{C}$ in patients with type 2 diabetes solely on oral medications. As a contribution to the ongoing discussion of SMBG testing in non-insulin-dependent patients with diabetes, our data suggest that regular patient-provider interaction with actionable feedback, such as the IBGMS reporting model followed in this study, justifies SMBG in this patient group. We recommend the incorporation of IBGMS reporting into any new and previously established SMBG therapies.

Author affiliations

${ }^{1}$ Department of Biochemistry, University of British Columbia, Vancouver, British Columbia, Canada

${ }^{2}$ Department of Zoology, University of British Columbia, Vancouver, British Columbia, Canada

${ }^{3}$ Endocrine Research Society, Vancouver, British Columbia, Canada

${ }^{4}$ Department of Medicine, University of British Columbia, Vancouver, British Columbia, Canada

${ }^{5}$ Department of Endocrinology and Metabolism, St. Paul's Hospital, Vancouver, British Columbia, Canada

Acknowledgements The authors wish to pay our respects to Dr Hugh Tildesley for his lifetime passion for diabetes management and for his pioneering work in the field of internet blood glucose monitoring. He will be greatly missed by both his peers and patients. Portions of this study have been presented in abstract form at the International Diabetes Federation World Diabetes Congress, Vancouver, Canada, on December 2015.

Contributors HDT is the guarantor of this work and, as such, had full access to all of the data in the study and takes responsibility for the integrity of the data and accuracy of the data analysis. HDT, NC, and DS wrote, reviewed, and edited the manuscript. NC and DS collected data with assistance from JAP and BP. The manuscript was reviewed/edited by MP, AW, JAP and BP. All authors read and approved the final manuscript. 
Funding This work was supported by the Endocrine Research Society, Vancouver, British Columbia, Canada.

Competing interests None declared.

Ethics approval Providence Health Research Ethics Board.

Provenance and peer review Not commissioned; externally peer reviewed.

Data sharing statement Original raw data are encrypted and will be kept on file at the site of collection for 5 years after publication. It will be accessible only by the authors or with proper legal authority.

Open Access This is an Open Access article distributed in accordance with the Creative Commons Attribution Non Commercial (CC BY-NC 4.0) license, which permits others to distribute, remix, adapt, build upon this work noncommercially, and license their derivative works on different terms, provided the original work is properly cited and the use is non-commercial. See: http:// creativecommons.org/licenses/by-nc/4.0/

\section{REFERENCES}

1. The Diabetes Control and Complications Trial Research Group. The effect of intensive treatment of diabetes on the development and progression of long-term complications in insulin-dependent diabetes mellitus. N Engl J Med 1993;329:977-86.

2. UK Prospective Diabetes Study (UKPDS) Group. Intensive blood-glucose control with sulphonylureas or insulin compared with conventional treatment and risk of complications in patients with type 2 diabetes (UKPDS 33). Lancet 1998;352:837-53.

3. Bergenstal RM, Gavin JR, Global Consensus Conference on Glucose Monitoring Panel. The role of self-monitoring of blood glucose in the care of people with diabetes: report of a global consensus conference. Am J Med 2005;118(Suppl 9A):1S-6S

4. Garg S, Hirsch IB. Self-monitoring of blood glucose. Int J Clin Pract Supp/ 2010:166:1-10.

5. Coster S, Gulliford M, Seed P, et al. Monitoring blood glucose control in diabetes mellitus: a systematic review. Health Technol Assess 2000;12:i-iv, 1-93.

6. Skeie S, Kristensen GCS, Sandberg S. Self-monitoring of blood glucose in type 1 diabetes patients with insufficient metabolic control: focused self-monitoring of blood glucose intervention can lower glycated hemoglobin A1C. J Diabetes Sci Technol 2009;3:83-8.

7. Karter A, Ackerson L, Darbinian J, et al. Self-monitoring of blood glucose levels and glycemic control: the Northern California Kaiser Permanente Diabetes Registry. Am J Med 2001;111:1-9.

8. Murata $\mathrm{GH}$, Shah JH, Hoffman RM, et al. Diabetes Outcomes in Veterans Study (DOVES): Intensified blood glucose monitoring improves glycaemic control in stable, insulin-treated veterans with type 2 diabetes. Diabetes Care 2003;26:1759-63.

9. Allemann S, Houriet C, Diem P, et al. Self-monitoring of blood glucose in non-insulin treated patients with type 2 diabetes: a systematic review and meta-analysis. Curr Med Res Opin 2009;25:2903-13.

10. Hirsch IB, Bode BW, Childs BP, et al. Self-monitoring of Blood Glucose (SMBG) in insulin- and non-insulin-using adults with diabetes: consensus recommendations for improving SMBG accuracy, utilization, and research. Diabetes Technol Ther 2008;10:419-39.

11. Tildesley $\mathrm{H}$, Mazanderani $\mathrm{A}, \mathrm{Chan} \mathrm{J}$, et al. Efficacy of $\mathrm{A} 1 \mathrm{c}$ reduction using internet intervention in patients with type 2 diabetes treated with insulin. Can J Diab 2011;35:250-3.

12. Tildesley HD, Mazanderani AB, Ross SA. Effect of internet therapeutic intervention on $\mathrm{HbA} 1 \mathrm{C}$ levels in patients with type 2 diabetes treated with insulin. Diabetes Care 2010;33:1738-40.

13. Tildesley HD, Wright AM, Chan JH, et al. A comparison of internet monitoring with continuous glucose monitoring in insulin-requiring type 2 diabetes mellitus. Can J Diabetes 2013;37:305-8.

14. Deng L, White A, Pawlowska M, et al. Cost-benefit analysis of internet therapeutic intervention on patients with diabetes. Int $J$ Endocrinol Metab 2005;13:e22803.

15. Minder AE, Albrecht D, Schäefer J, et al. Frequency of blood glucose testing in well educated patients with diabetes mellitus type 1: how often is enough? Diabetes Res Clin Pract 2013;101:57-61.

16. Miller K, Beck R, Bergenstal R, et al. Evidence of a strong association between frequency of self-monitoring of blood glucose and hemoglobin a1c levels in $\mathrm{t} 1 \mathrm{~d}$ exchange clinic registry participants. Diabetes Care 2013;36:2009-14.

17. Tildesley HD, Conway ME, Deng L, et al. The effectiveness of internet intervention on 926 patients with diabetes for up to 30 months. Can J Diabetes 2015;39:216-20. 